\title{
Significant association of DRD2 and ANKK1 genes with rural heroin dependence and relapse in men
}

\author{
Milena Lachowicz, ${ }^{1, \mathrm{~B}-\mathrm{F}}$, Jolanta Chmielowiec ${ }^{2, \mathrm{~B}, \mathrm{D}, \mathrm{F} \oplus}{ }^{\oplus}, \mathrm{Krzysztof}$ Chmielowiec ${ }^{2, \mathrm{~B}, \mathrm{D}, \mathrm{F} \oplus}{ }^{\oplus}$, \\ Aleksandra Suchanecka ${ }^{3, C-F}$, Jolanta Masiak $^{4, D, F}{ }^{\infty}$, Monika Michałowska-Sawczyn $^{1, C-D, F} \oplus$, \\ Bożena Mroczek ${ }^{5, C, E-F \oplus}$, Artur Mierzecki ${ }^{6, C, F} \oplus$, Iwona Ciechanowicz ${ }^{7, E-F}{ }^{\circ}$, Anna Grzywacz ${ }^{3, A, C-F} \oplus$ \\ ${ }^{1}$ Department of Physical Education and Social Science, University of Physical Education and Sport, Gdańsk, Poland \\ ${ }^{2}$ Department of Hygiene and Epidemiology, Collegium Medicum, University of Zielona Góra, Poland \\ ${ }^{3}$ Independent Laboratory of Health Promotion of the Pomeranian Medical University, Szczecin, Poland \\ ${ }^{4}$ Neurophysiological Independent Unit, Department of Psychiatry, Medical University, Lublin, Poland \\ ${ }^{5}$ Department of Humanities in Medicine, Pomeranian Medical University, Szczecin, Poland \\ ${ }^{6}$ Independent Laboratory of Family Physician Education, Pomeranian Medical University, Szczecin, Poland \\ ${ }^{7}$ Pomeranian Medical University, Szczecin, Poland \\ A - Research concept and design, B - Collection and/or assembly of data, C - Data analysis and interpretation, \\ $D$ - Writing the article, E-Critical revision of the article, F-Final approval of article
}

Lachowicz M, Chmielowiec J, Chmielowiec K, Suchanecka A, Masiak J, Michałowska-Sawczyn M, Mroczek B, Mierzecki A, Ciechanowicz I, Grzywacz A. Significant association of DRD2 and ANKK1 genes with rural heroin dependence and relapse in men. Ann Agric Environ Med. 2020; 27(2): 269-273. doi: 10.26444/aaem/119940

\section{Abstract}

Introduction. Substance abuse significantly influences human health and may induce problems with social functioning worldwide. Numerous genetic and environmental risk factors, as well as their interactions, accelerate the development of drug addiction. Etiologically, the dopaminergic mesocorticolimbic reward pathways are related to psychoactive substance addiction, and the reward properties of heroin are connected with changes in the mesolimbic dopaminergic system.

Objective. The aim of this study is a haplotypic analysis of subjects addicted to polysubstance. However, with the knowledge that this is not a homogenous subgroup, it was decided to separate and analyze homogenous subgroups of subjects in order to find specific haplotypic variants among them. The subjects in the subgroups were addicted to heroin, and subjects with more than two relapses in the past two years.

Materials and method. The study group comprised of 301 polysubstance addicted rural male subjects. From this group, 2 homogenous subgroups of subjects were isolated and additionally analyzed: (1) a group of heroin addicted subjects ( $n=61)$, and (2) a group of heroin-addicted subjects with at least two relapses in the last two years $(n=21)$. The group consisting of all polysubstance addicted rural subjects and both homogenous subgroups were analyzed against a control group of non-addicted subjects $(\mathrm{n}=300)$, matching gender and age. Five polymorphisms in the DRD2/ANKK1 region were analyzed: rs1076560, rs1800498, rs1079597, rs6276 in the DRD2 gene, and rs1800497 in the ANKK1 gene.

Results. A statistically significant haplotype association was found in analysis of the heroin addicted subjects, compared to controls, and two possible trends - when comparing the whole group of addicted subjects to controls, and in relapse subgroups, compared to the controls.

Conclusion. The results obtained showed that haplotypes indicate a part of the biological component of addiction.

Key words

Addiction, heroin, dopamine, haplotypes

\section{INTRODUCTION}

The worldwide substance use and abuse significantly influences human health and may induce problems with social functioning. It is believed that numerous genetic and environmental risk factors, as well as their relations, may accelerate the development of drug addiction [1]. However, it is still not clear which group of genes may be definitely connected with susceptibility. Analysis of heroin properties allow to relate its reward influence with changes in the mesolimbic dopaminergic system [2]. Additionally, dopamine receptor expression may be of importance in

Address for correspondence: Anna Grzywacz, Independent Laboratory of Health Promotion of the Pomeranian Medical University in Szczecin, Poland E-mail: grzywacz.anna.m@gmail.com

Received: 26.02.2020; accepted: 31.03.2020; first published: 12.05 .2020 the development of heroin dependence (HD), specifically in relation to the D2 dopamine receptor (DRD2) $[3,4]$. Dopamine-related and dopamine-nonrelated mechanisms facilitate the reinforcing effects of drugs of the opioid group. Etiologically, the dopaminergic mesocorticolimbic reward pathways are related to psychoactive substance addiction $[5,6,7]$. Addictive substances temporarily increase the level of extracellular dopamine in the ventral striatum, which increases the speed of the learning process and facilitates compulsiveness of substance abuse [8]. The mesolimbic dopaminergic pathway is activated by substance of abuse, and dopamine is involved in all stages of the development of addiction [9].

The current study investigates the association between genes which influence dopamine production and heroin addiction. Although different ancestral populations are also 
at risk of developing drug addiction, differences in linkage disequilibrium (LD) and allele frequencies may indicate the presence of some specific genetic risk factors. The genes selected for this analysis include encoding DA (dopamine) receptor and ANKK1 (Ankyrin repeat and kinase domain containing 1) protein kinase. The dopamine receptor 2 gene was chosen for this study due to the importance of dopamine in the addiction process, which is supported by many studies $[10,11,12]$. Since both genes are located next to one another and are possibly clustered together with NCAM1 (Neural cell adhesion molecule 1) and TTC12 (Tetratricopeptide Repeat Domain 12 gene) genes due to the regulatory functions that are to be maintained across evolution to preserve phenotypic integrity [13], the $A N K K 1$ gene was also analyzed in this study.

Earlier observations indicate that DRD2 may be treated as one of the most interesting candidate gene in studies on heroin dependence (HD). Previously, the human DRD2 gene was thought to be located on chromosome 11q22-23 [14], now it is known that it is shorter and on chromosome 11q23.2. Interestingly, one of the most often analyzed polymorphic sites, Taq1A (rs1800497), is located in the ANKK1 gene and not in DRD2. The Taq1A is in linkage disequilibrium with variants located in the dopamine receptor 2 gene, which confirms its functional relation, and both genes are often analyzed together in the context of addictions $[15,16]$. It is also of great importance that the ANKK1 gene in the central nervous system is expressed only in astrocytes which, due to bilateral communication with synapse, are thought to be part of the synapse [17]. ANKK1 belongs to the RIP (ReceptorInteracting Protein) serine/threonine kinase family. These kinases are important in cell proliferation, differentiation and activate transcription factors [18]. $D R D 2$ gene is probably regulated by ANKK1 through NF-kappaB (Nuclear FactorkappaB). ANKK1 is activated by apomorphine-dopaminergic agonist, which indicates another link with the dopaminergic system [19].

Other polymorphisms studied in the $D R D 2$ gene region in the context of addiction include: the TaqIB (rs1079597), TaqID (rs1800498) polymorphisms, and the deletion of cytosine 141 (-141C Ins/Del, rs1799732). There is high linkage disequilibrium (LD) between TaqIA and TaqIB in Asian, American, and European populations [20, 21]. However, low LD has been noted in relation between these two polymorphisms and the $-141 \mathrm{C}$ Ins/ Del polymorphism [22]. The TaqIA polymorphism is located in ANKK1, whereas the TaqIB, TaqID and -141C Ins/Del variants are located in the intron and promoter regions of $D R D 2$, respectively. Some studies have noted the relationship between addictive behaviours and TaqIA minor allele and heroin, cocaine, and alcohol and tobacco dependence $[1,23,24,25,26$, 27]. The TaqIB minor allele appears more often in the HD context, alcohol dependence and poly-substance abuse [1, $28,29,30]$. As mentioned before, ANKK1 is located very close to DRD2, and the LD between SNPs in both genes is high. This is the coding region of ANKK1 where the TaqIA polymorphism (rs1800497) is located. Potentially, ANKK1 and the dopaminergic system are interrelated [31]. There have been several supporting reports on the association between dopamine-connected genes and heroin or cocaine addiction. The relationship between ANKK1/DRD2 SNPs and heroin or cocaine addiction/abuse has been observed in different populations $[1,28,32,33,34,35,36,37,38,39]$.
The biological basis of addiction is still not well understood, and although $50 \%$ of the risk factors has been attributed to the genetic component, the roles of the myriad of individual candidate genes in conferring genetic risk are not well characterized. Haplotype analyses may shed light on the collective risk profile in this context. Therefore, the current study focuses on the analysis of haplotypes in people addicted to heroin. A thorough analysis was also carried out of this genetic relationship in connection with 5 genetic markers for the DRD2 and $A N K K 1$ genes to assess the influence of DRD2/ $A N K K 1$ variants in the pathogenesis of heroin dependence.

\section{MATERIALS AND METHODS}

Subjects. After the approval of the Bioethics Committee of the Pomeranian Medical University (KB-0012/106/16), as well as an informed, written consent of the subjects had been granted, the study was carried out in the Independent Laboratory of Health Promotion at the Pomeranian Medical University in Szczecin, Poland. The study involved 601 subjects -301 men from rural areas (mean age $=28$, $\mathrm{SD}=6.45$ ) addicted to more than two psychoactive substances (polysubstance addiction), staying in a rehabilitation centre, and 300 healthy, non-addicted men (mean age $=22$, $\mathrm{SD}=4.57)$. The research and control groups were examined by a psychiatrist. For the control group, addiction and other mental diseases were excluded by applying the M.I.N.I. Mini International Neuropsychiatric Interview. The main aim of this study was haplotypic analysis of polysubstance addicted subjects; however, knowing that this is not a homogenous subgroup, it was decided to separate homogenous subgroups of subjects and analyze them separately in order to find specific haplotypic variants among them. The subgroups comprised subjects addicted to heroin and subjects with more than two relapses in the past two years.

Genotyping. Blood from the ulnar vein was collected from all subjects. DNA was isolated using standard procedures. The PCR method was used to genotype samples. Genotyping was performed by fluorescence resonance energy transfer using the real-time PCR method on the LightCycler ${ }^{\circledR} 480$ II System (Roche Diagnostic, Basel, Switzerland). PCR was performed according to standard procedures. The fluorescence signal was plotted against temperature to provide melting curves for each sample. Peaks for $\mathrm{rs} 1800497$ were obtained at $58.95^{\circ} \mathrm{C}$ for the $\mathrm{T}$ allele and $67.17^{\circ} \mathrm{C}$ for the $\mathrm{C}$ allele. For rs6276, they were at $59.14^{\circ} \mathrm{C}$ for the $\mathrm{G}$ allele and at $67.66^{\circ} \mathrm{C}$ for the $\mathrm{A}$ allele. For rs $1076560-57.13^{\circ} \mathrm{C}$ for the A allele and $64.40^{\circ} \mathrm{C}$ for the $\mathrm{C}$ allele. For rs $1800498-57.87^{\circ} \mathrm{C}$ for the $\mathrm{T}$ allele and $66.34^{\circ} \mathrm{C}$ for the $\mathrm{C}$ allele. For $\operatorname{rs} 1079597-57.41^{\circ} \mathrm{C}$ for the $\mathrm{G}$ allele and $62.25^{\circ} \mathrm{C}$ for the A allele. Figure 1 shows selected polymorphic loci.

Statistical analysis. Haplotype analysis was carried out using R software with Bioconductor packages haplo.stats and genetics. Linkage Disequilibrium and graphical image of the LD were performed by Haploview ver. 4.2 (Fig. 2).

Location of 5 polymorphisms in the DRD2/ANKK1 genes region is shown in the upper panel; output of Haploview version 4.2 is shown in the lower panel. 


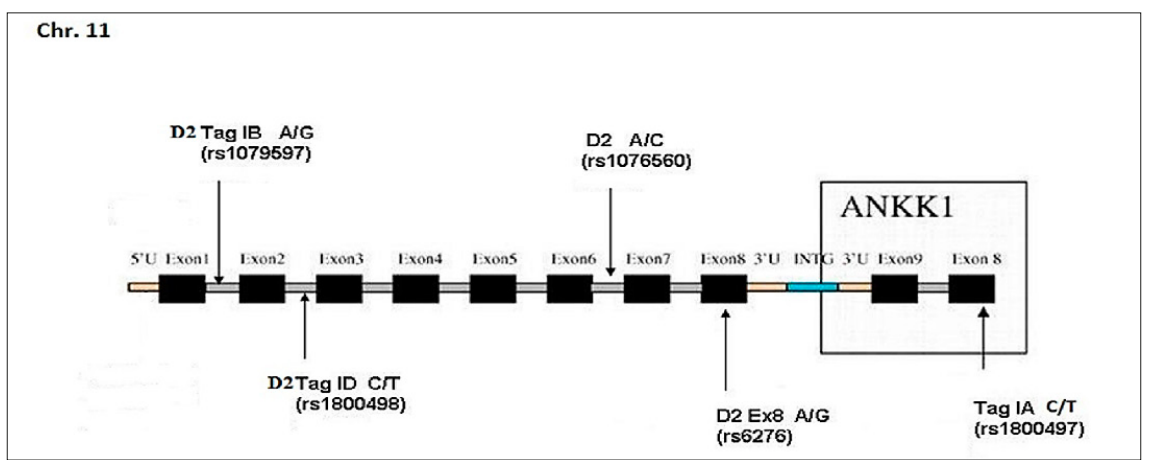

Figure 1. Localization of polymorphisms applied within DRD2 and ANKK1 gene. 5 selected markers provided a coverage of DRD2/ANKK1 as a result of the random SNP selection method.
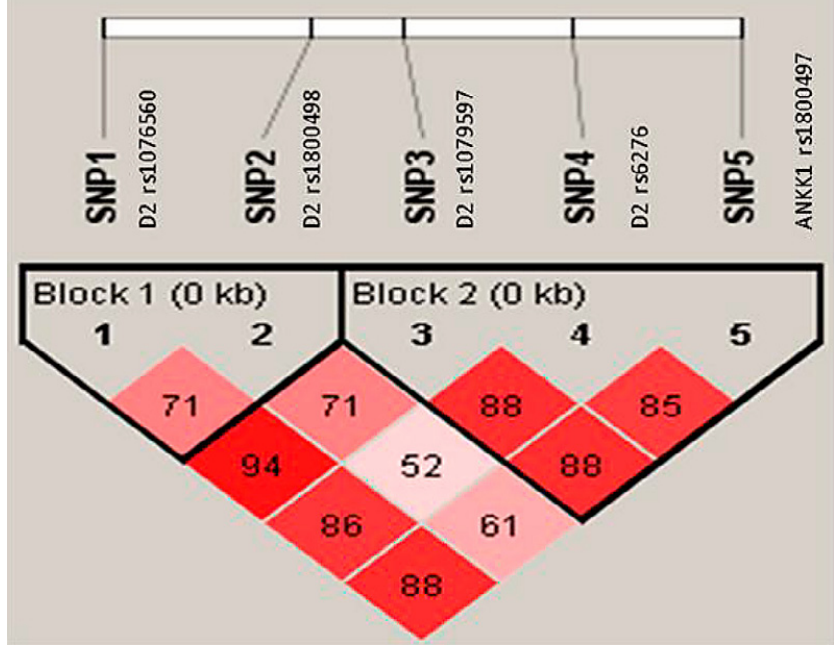

Figure 2. Linkage Disequilibrium structure of 5 polymorphisms in the DRD2/ ANKK1 genes region.

D' - Lewontin's D'; SNP1 - polymorphism DRD2 rs1076560; SNP2 - polymorphism DRD2 TagID rs1800498; SNP3 - polymorphism DRD2 TagIB rs1079597; SNP4 polymorphism DRD2 Ex8 rs6276; SNP5 - polymorphism ANKK1 TagIA rs1800497

\section{RESULTS}

Haplotype analysis. Figure 2 shows the haplotype blocks and Linkage Disequilibrium tructure of the DRD2 and $A N K K 1$, as

Table 1. Frequency of haplotypes built from polymorphisms: $D R D 2$ rs1076560 (A/C), DRD2 Tag 1D rs1800498 (C/T), DRD2 Tag 1B rs1079597 (A/G), DRD2 exon 8 rs6276 (A/G) and Taq1A rs1800497 (C/T) of the ANKK1 gene in rural individuals addicted to psychoactive substances and in the control group

\begin{tabular}{lccccc}
\hline Haplotype & Hap-Score & p.val & $\begin{array}{c}\text { Overall } \\
\text { frequency }\end{array}$ & $\begin{array}{c}\text { Control } \\
(\mathrm{n}=300)\end{array}$ & $\begin{array}{c}\text { Case } \\
(\mathrm{n}=301)\end{array}$ \\
\hline C-T-A-A-C & -1.90899 & 0.05626 & 0.00517 & 0.00950 & NA \\
\hline C-T-G-G-C & -1.25506 & 0.20946 & 0.08429 & 0.09393 & 0.07208 \\
\hline A-C-A-A-C & -0.92437 & 0.35529 & 0.00514 & 0.00703 & 0.00204 \\
\hline A-T-A-A-T & -0.81511 & 0.41501 & 0.01455 & 0.01801 & 0.01079 \\
\hline A-T-G-A-C & -0.45171 & 0.65147 & 0.00540 & 0.00625 & 0.00418 \\
\hline C-C-G-G-T & -0.14250 & 0.65147 & 0.00485 & 0.00532 & 0.00462 \\
\hline C-C-G-G-C & 0.13657 & 0.89137 & 0.25167 & 0.24972 & 0.25189 \\
\hline C-T-G-A-C & 0.34437 & 0.73056 & 0.44086 & 0.43744 & 0.44892 \\
\hline C-C-G-A-C & 0.45921 & 0.64608 & 0.00491 & 0.00392 & 0.00581 \\
\hline C-T-G-A-T & 0.55053 & 0.58195 & 0.02131 & 0.01811 & 0.02416 \\
\hline A-C-A-A-T & 1.01456 & 0.31031 & 0.14176 & 0.13103 & 0.15230 \\
\hline
\end{tabular}

NA - data not available well as the D' and $\mathrm{r} 2$ values (for all variants). Two main blocks were detected from 5 polymorphisms. Block 1 (rs1076560, rs1800498) included two SNPs from the intron 6 and intron 2 of DRD2. Block 2 (rs1079597, rs6276 and rs1800497) included two SNPs within intron 1 and exon 6 of DRD2 and exon 8 of ANKK1 (Fig. 2). Four associations were noted during haplotypic analysis, including possible trend $(\mathrm{p}=0.05626) \mathrm{C}-\mathrm{T}-\mathrm{A}-\mathrm{A}-\mathrm{C}$ (Tab. 1). The Hap-Score of this haplotype equals $-1,90899$, which suggests that this is a protective haplotypic variant.

During haplotype analysis of selected rural heroindependent patients, a statistically more significant frequency of haplotype C-T-G-A-T was observed in the addicted group than in the control group $(\mathrm{p}=0.03534)$ (Table 2$)$. Similarly, when analyzing heroin addicts with more than two relapses, haplotype C-T-G-A-C was more frequent in cases showing a possible .....? (Tab. 3).

Table 2. Frequency of haplotypes built from polymorphisms: $D R D 2$ rs1076560 (A/C), DRD2 Tag1D rs1800498 (C/T), DRD2 Tag1B rs1079597 (A/G), DRD2 exon 8 rs6276 (A/G) and Taq1A rs1800497 (C/T) of the ANKK1 gene in rural individuals addicted to heroin and in the control group.

\begin{tabular}{lccccc}
\hline Haplotype & Hap-Score & p.val & $\begin{array}{c}\text { Overall } \\
\text { frequency }\end{array}$ & $\begin{array}{c}\text { Control } \\
(\mathrm{n}=300)\end{array}$ & $\begin{array}{c}\text { Case } \\
(\mathrm{n}=61)\end{array}$ \\
\hline C-C-G-G-C & -1.07326 & 0.28315 & 0.24330 & 0.25016 & 0.20492 \\
\hline C-T-A-A-C & -0.93538 & 0.34959 & 0.00791 & 0.00954 & $\mathrm{NA}$ \\
\hline A-T-A-A-T & -0.93538 & 0.50307 & 0.01618 & 0.01808 & 0.00820 \\
\hline A-C-A-A-T & -0.53418 & 0.59322 & 0.12883 & 0.13148 & 0.11475 \\
\hline C-T-G-G-C & -0.19909 & 0.84219 & 0.09316 & 0.09407 & 0.09011 \\
\hline C-T-G-A-C & 1.89991 & 0.05745 & 0.45186 & 0.43787 & 0.52465 \\
\hline C-T-G-A-T & 2.10446 & $\mathbf{0 . 0 3 5 3 4}$ & 0.02188 & 0.01585 & 0.04912 \\
\hline
\end{tabular}

NA - data not available

Table 3. Frequency of haplotypes built from polymorphisms: $D R D 2$ rs1076560 (A/C), DRD2 Tag1D rs1800498 (C/T), DRD2 Tag1B rs1079597 (A/G), DRD2 exon 8 rs6276 (A/G) and Taq1A rs1800497 (C/T) of the ANKK1 gene in rural individuals addicted to heroin with relapses (more than 2 treatments) and in the control group

\begin{tabular}{lccccc}
\hline Haplotype & Hap-Score & p.val & $\begin{array}{c}\text { Overall } \\
\text { frequency }\end{array}$ & $\begin{array}{c}\text { Control } \\
(\mathbf{n = 3 0 0})\end{array}$ & $\begin{array}{c}\text { Case } \\
(\mathbf{n = 2 1 )}\end{array}$ \\
\hline C-T-G-G-C & -1.36089 & 0.17355 & 0.08956 & 0.09407 & 0.02381 \\
\hline A-T-A-A-T & -0.75358 & 0.45110 & 0.01684 & 0.01808 & NA \\
\hline A-C-A-A-T & -0.69545 & 0.48677 & 0.12911 & 0.13148 & 0.09524 \\
\hline C-T-A-A-C & -0.54900 & 0.58301 & 0.00891 & 0.00954 & NA \\
\hline C-C-G-G-C & -0.43307 & 0.66496 & 0.24886 & 0.25016 & 0.21429 \\
\hline C-T-G-A-T & 1.50559 & 0.13217 & 0.01877 & 0.01585 & 0.04762 \\
\hline C-T-G-A-C & 1.95937 & $\mathbf{0 . 0 5 0 0 7}$ & 0.44700 & 0.43787 & 0.59524
\end{tabular}

NA - data not available 


\section{DISCUSSION}

The study focused on the analysis of haplotypes composed of polymorphic variants located in the DRD2/ANKK1 region in subjects addicted to psychoactive substances, and in a group of patients from a control group. During the first analysis of 301 rural patients from the drug rehabilitation centre, the result at a level of possible trend was observed, which indicated the probable role of a protective haplotype. Interestingly, the significance or possible trend appeard during the analysis of all HD subjects and those with two or more relapses in the last two years. Haplotypes C-T-GA-T and C-T-G-A-C are typical of the HD group. Despite the small number of subgroups, a specific haplotype was obtained at a significant level. This may be related to the selection of polymorphic sites building those haplotypes, and their association with the addiction by means of the dopaminergic system in the brain.

Because dopamine is a key factor in the transmission of signal by neurons in the reward system, a research study on the variants in addictive disorders is of great importance. It is worth emphasizing that both the limbic and cortical areas are the locations of D1 receptors expression, whereas the ventral tegmental area, nucleus accumbens (D2), and in the Islands of Calleja (D3) are the sites of D2 and D3 receptors expression; however, they both facilitate the addictive processes [40].

The ANKK1 TaqIA is included in the group of key variants involved in the process of addiction, although recent research has indicated that variants found within ANKK1 and TTC12 may be treated as phenotypes influencing addiction [15, 19, 41, 42]. The protective effect of the G-C-A haplotype, the A-T-G haplotype (comprising opposite alleles) in the same three variants (rs11604671-rs4938015-rs2303380) has been observed to increase risk of nicotine dependence in two different populations [43]. Moreover, haplotypes in the same region influence the risk of developing alcohol dependence [44].

The presence of $T$ allele (TaqIB B1 allele) in the rs1079597 among people of Caucasian origin was associated with an undoubtedly lower number of binding sites, and a decreased density of dopamine D2 receptors, compared to individuals without this variant $[45,46]$. Wang et al. observed that DRD2 was expressed in opiate-dependent subjects on a lower level when compared with controls. In the current study, a higher number of the $\mathrm{T}$ allele was found in the heroin-dependent individuals, which allows the conclusion that the $\mathrm{T}$ allele of rs1079597 increases the probability of developing heroin dependence [47]. The same conclusions are found in other studies $[1,28]$.

It was also observed that heroin dependence remained in significant association with DRD2 rs6275. A lower frequency of heroin dependence was found in subjects with the AA genotype, which shows that the predisposition of rs6275 AA carriers to develop a heroin addiction is decreased. Variant rs6275 is a His 313 synonymous polymorphism in the sixth exon of the $D R D 2$ gene. It was mentioned as a factor having loose association with disease vulnerability in the Indian population, and as a polymorphic locus which modulates methadone treatment $[48,49]$. Methadone is effective in treating opioid dependence. Nevertheless, its influence is conditioned with a personalized approach to methadone maintenance with basis in genetics. There is evidence of a strong correlation between bias in synonymous codon usage and the level of gene expression with the rs6275 SNP [50]. The minor $T$ allele of rs6275 is found close to the synonymous rs6277 SNP (Pro319Pro), which results in a modified mRNA folding, decrease in mRNA stability and protein synthesis, as well as decreased expression of D2 receptor in the context of dopamine regulatory system [51]. Taking into account the relationship between rs6275 and rs6277, the molecular functioning according to which they act may be of a high similarity [49].

\section{CONCLUSIONS}

This study shows the association of haplotype built from polymorphic variants located in DRD2/ANKK1 region with heroin dependence, and possible trends with substance dependence and heroine relapse. At this stage, it is not possible to state whether the statistically significant haplotypes discovered are typical of HD or a higher relapse rate. Studies by other researchers, as mentioned above, are differ from those obtained in the current study. However, they do indicate a similar research direction; therefore, it is necessary to carry out larger-scale studies. Nevertheless, the significance obtained may determine the direction of further research, both in the group of subjects dependent on psychoactive substances (e.g. polysubstance drug abuse) and other homogeneous subgroups.

\section{FUNDING}

This research was funded by National Science Centre, Poland, grant number UMO-2015/19/B/NZ7/03691.

\section{CONFLICTS OF INTEREST}

The authors declare they have no conflict of interest.

\section{REFERENCES}

1. Vereczkey A, Demetrovics Z, Szekely A, Sarkozy P, Antal P Szilagyi A, et al. Multivariate analysis of dopaminergic gene variants as risk factors of heroin dependence. PLoS One. 2013; 8e66592.

2. Levran O, Randesi M, da Rosa JC, Ott J, Rotrosen J, Adelson M, et al. Overlapping dopaminergic pathway genetic susceptibility to heroin and cocaine addictions in African Americans. Ann Hum Genet. 2015; 79: 188-98.

3. Burns JA, Kroll DS, Feldman DE, Kure Liu C, Manza P, Wiers CE, et al. Molecular Imaging of Opioid and Dopamine Systems: Insights into the Pharmacogenetics of Opioid Use Disorders. Front Psychiatry. 2019; 10: 626.

4. Zhou Y, Leri F, Cummins E, Kreek MJ. Individual differences in gene expression of vasopressin, D2 receptor, POMC and orexin: vulnerability to relapse to heroin-seeking in rats. Physiol Behav. 2015; 139: 127-135.

5. Solinas M, Belujon P, Fernagut PO, Jaber M, Thiriet N. Dopamine and addiction: what have we learned from 40 years of research. J Neural Transm (Vienna). 2019; 126: 481-516.

6. Keramati M, Gutkin B. Imbalanced decision hierarchy in addicts emerging from drug-hijacked dopamine spiraling circuit. PLoS One. 2013; 8: e61489.

7. Ikemoto S, Bonci A. Neurocircuitry of drug reward. Neuropharmacology. 2014; 76 Pt B: $329-41$

8. Girault JA. Signaling in striatal neurons: the phosphoproteins of reward, addiction, and dyskinesia. Prog Mol Biol Transl Sci. 2012; 106: 33-62.

9. Chen YH, Lin BJ, Hsieh TH, Kuo TT, Miller J, Chou YC, et al. Differences in Nicotine Encoding Dopamine Release between the Striatum and 
Shell Portion of the Nucleus Accumbens. Cell Transplant. 2019; 28: $248-261$.

10. Patriquin MA, Bauer IE, Soares JC, Graham DP, Nielsen DA. Addiction pharmacogenetics: a systematic review of the genetic variation of the dopaminergic system. Psychiatr Genet. 2015; 25: 181-93.

11. Linden J, James AS, McDaniel C, Jentsch JD. Dopamine D2 Receptors in Dopaminergic Neurons Modulate Performance in a Reversal Learning Task in Mice. eNeuro. 2018; 5: pii: ENEURO.0229-17.2018

12. Sznabowicz M, Jasiewicz A, Iskra-Trifunović J, Małecka I, Karakiewicz B, Kotwas A, et al. Case-control study analysis of DRD2 gene polymorphisms in drug addicted patients. Psychiatr Pol. 2018; 52: 1013-1022.

13. Mota NR, Araujo-Jnr EV, Paixao-Cortes VR, Bortolini MC, Bau $\mathrm{CH}$. Linking dopamine neurotransmission and neurogenesis: The evolutionary history of the NTAD (NCAM1-TTC12-ANKK1-DRD2) gene cluster. Genet Mol Biol. 2012; 35: 912-8.

14. Grandy DK, Litt M, Allen L, Bunzow JR, Marchionni M, Makam H, et al. The human dopamine $\mathrm{D} 2$ receptor gene is located on chromosome 11 at q22-q23 and identifies a TaqI RFLP. Am J Hum Genet, 1989; 45: 778-785.

15. Wagner AK, Scanlon JM, Becker CR, Ritter AC, Niyonkuru C, Dixon $\mathrm{CE}$, et al. The influence of genetic variants on striatal dopamine transporter and D2 receptor binding after TBI. J Cereb Blood Flow Metab. 2014; 34: 1328-39.

16. Grzywacz A, Chmielowiec J, Chmielowiec K, Mroczek B, Masiak J, Suchanecka A, et al. The Ankyrin Repeat and Kinase Domain Containing 1 Gene Polymorphism (ANKK1 Taq1A) and Personality Traits in Addicted Subjects. Int J Environ Res Public Health. 2019; 16: pii: E2687.

17. Araque A, Parpura V, Sanzgiri RP, Haydon PG. Tripartite synapses: Glia, the unacknowledged partner. Trends Neurosc. 1999; 22: 208-215.

18. Meylan E, Tschopp J. The RIP kinases: Crucial integrators of cellular stress. Trends Biochem Sc 2005; 30: 151-159.

19. Huang W, Payne TJ, Ma JZ, Beuten J, Dupont RT, Inohara N, Li MD. Significant association of ANKK1 and detection of a functional polymorphism with nicotine dependence in an African American Sample. Neuropsychopharmacology. 2009; 34: 319-330.

20. Jasiewicz A, Samochowiec A, Samochowiec J, Małecka I, Suchanecka A, Grzywacz A. Suicidal behavior and haplotypes of the dopamine receptor gene (DRD2) and ANKK1 gene polymorphisms in patients with alcohol dependence--preliminary report. PLoS One. 2014; 9: el11798.

21. Huang SY, Lin WW, Ko HC, Lee JF, Wang TJ, Chou YH, et al. Possible interaction of alcohol dehydrogenase and aldehyde dehydrogenase genes with the dopamine $\mathrm{D} 2$ receptor gene in anxiety-depressive alcohol dependence. Alcohol Clin Exp Res. 2004; 28: 374-384.

22. Arinami T, Gao M, Hamaguchi H, Toru M. A functional polymorphism in the promoter region of the dopamine $\mathrm{D} 2$ receptor gene is associated with schizophrenia. Hum Mol Genet. 1997; 6: 577-582.

23. Ma Y, Yuan W, Jiang X, Cui WY, Li MD. Updated findings of the association and functional studies of DRD2/ANKK1 variants with addictions. Mol Neurobiol. 2015; 51: 281-99.

24. Tsou CC, Chou HW, Ho PS, Kuo SC, Chen CY, Huang CC, et al. DRD2 and ANKK1 genes associate with late-onset heroin dependence in men. World J Biol Psychiatry. 2019; 20: 605-615.

25. Spellicy CJ, Harding MJ, Hamon SC, Mahoney JJ 3rd, Reyes JA, Kosten TR, et al. A variant in ANKK1 modulates acute subjective effects of cocaine: a preliminary study. Genes Brain Behav. 2014; 13: 559-64.

26. Mignini F, Napolioni V, Codazzo C, Carpi FM, Vitali M, Romeo M, et al. DRD2/ANKK1 TaqIA and SLC6A3 VNTR polymorphisms in alcohol dependence: association and gene-gene interaction study in a population of Central Italy. Neurosci Lett. 2012; 522: 103-107.

27. Voisey J, Swagell CD, Hughes IP, van Daal A, Noble EP, Lawford BR, et al. A DRD2 and ANKK1 haplotype is associated with nicotine dependence. Psychiatry Res. 2012; 196: 285-9.

28. Xu K, Lichtermann D, Lipsky RH, Franke P, Liu X, Hu Y, et al. Association of specific haplotypes of $\mathrm{D} 2$ dopamine receptor gene with vulnerability to heroin dependence in 2 distinct populations. Arch Gen Psychiatry. 2004; 61: 597-606.

29. Blum K, Noble EP, Sheridan PJ, Montgomery A, Ritchie T, Ozkaragoz $\mathrm{T}$, et al. Genetic predisposition in alcoholism: association of the D2 dopamine receptor TaqI B1 RFLP with severe alcoholics. Alcohol. 1993; 10: 59-67.

30. Smith SS, O'Hara BF, Persico AM, Gorelick DA, Newlin DB, Vlahov D, et al. Genetic vulnerability to drug abuse. The $\mathrm{D} 2$ dopamine receptor Taq I B1 restriction fragment length polymorphism appears more frequently in polysubstance abusers. Arch Gen Psychiatry. 1992; 49: $723-727$.
31. Ponce G, Quiñones-Lombraña A, Martín-Palanco NG, Rubio-Solsona E, Jiménez-Arriero MA, Palomo T, et al. The Addiction-Related Gene Ankk1 is Oppositely Regulated by D1R- and D2R-Like Dopamine Receptors. Neurotox Res. 2016; 29: 345-50.

32. Al-Eitan LN, Jaradat SA, Hulse GK, Tay G. Custom genotyping for substance addiction susceptibility genes in Jordanians of Arab descent. BMC Res Notes. 2012; 5: 497.

33. Clarke TK, Weiss AR, Ferarro TN, Kampman KM, Dackis CA, Pettinati HM, et al. The dopamine receptor D2 (DRD2) SNP rs1076560 is associated with opioid addiction. Ann Hum Genet. 2014; 78: 33-39.

34. Jacobs MM, Murray J, Byrd DA, Hurd YL, Morgello S. HIV-related cognitive impairment shows bi-directional association with dopamine receptor DRD1 and DRD2 polymorphisms in substance-dependent and substance-independent populations. J Neurovirol. 2013; 19: 495-504.

35. Zhang J, Yan P, Li Y, Cai X, Yang Z, Miao X, et al. A 35.8 kilobases haplotype spanning ANKK1 and DRD2 is associated with heroin dependence in Han Chinese males. Brain Res. 2018; 1688: 54-64.

36. Jabeen S, Pinsonneault JK, Sadee W, Lee SH, Zafar MM, Raja MS, et al. Significant association of DRD2 enhancer variant rs12364283 with heroin addiction in a Pakistani population. Ann Hum Genet. 2019; 83: 367-372.

37. Nelson EC, Lynskey MT, Heath AC, Wray N, Agrawal A, Shand FL, et al. ANKK1, TTC12, and NCAM1 polymorphisms and heroin dependence: importance of considering drug exposure. JAMA Psychiatry. 2013; 70: $325-333$.

38. Stolf AR, Cupertino RB, Müller D, Sanvicente-Vieira B, Roman T, et al. Effects of DRD2 splicing-regulatory polymorphism and DRD4 48 bp VNTR on crack cocaine addiction. J Neural Transm (Vienna). 2019; 126: 193-199.

39. Sullivan D, Pinsonneault JK, Papp AC, Zhu H, Lemeshow S, et al. Dopamine transporter DAT and receptor DRD2 variants affect risk of lethal cocaine abuse: a gene-gene-environment interaction. Transl Psychiatry. 2013; 3: e222.

40. Koob GF, Volkow ND. Neurocircuitry of addiction. Neuropsychopharmacology. 2010; 35: 217-238.

41. Noble EP. Addiction and its reward process through polymorphisms of the D2 dopamine receptor gene: a review. Eur J Psychiatr. 2000; 15: 79-89.

42. Radwan GN, El-Setouhy M, Mohamed MK, Hamid MA, Azem SA, Kamel O, et al. DRD2/ANKK1 TaqI polymorphism and smoking behavior of Egyptian male cigarette smokers. Nicotine Tobacco Res. 2007; 9: 1325-1329.

43. Gelernter J, Yu Y, Weiss R, Brady K, Panhuysen C, Yang BZ, et al. Haplotype spanning TTC12 and ANKK1, flanked by the DRD2 and NCAM1 loci, is strongly associated to nicotine dependence in two distinct American populations. Hum Mol Genet. 2006; 15: 3498-3507.

44. Yang BZ, Kranzler HR, Zhao H, Gruen JR, Luo X, Gelernter J, et al. Haplotypic variants in DRD2, ANKK1, TTC12, and NCAM1 are associated with comorbid alcohol and drug dependence. Alcohol Clin Exp Res. 2008; 32; 2117-2127.

45. Gluskin BS, Mickey BJ. Genetic variation and dopamine D2 receptor availability: a systematic review and meta-analysis of human in vivo molecular imaging studies. Transl Psychiatry. 2016; 6: e747.

46. Jönsson EG, Nöthen MM, Grünhage F, Farde L, Abumrad NN, Hitzemann RJ, et al. Polymorphisms in the dopamine D2 receptor gene and their relationships to striatal dopamine receptor density of healthy volunteers. Mol Psychiatry. 1999; 4: 290-296.

47. Wang GJ, Volkow ND, Fowler JS, Logan J, Abumard NN, Hitzemann RJ, et al. Dopamine D2 receptor availability in opiate-dependent subjects before and after naloxone-precipitated withdrawal. Neuropsychopharmacology. 1997; 16: 174-182.

48. Kukreti R, Tripathi S, Bhatnagar P, Gupta S, Chauhan C, Kubendran S, et al. Association of DRD2 gene variant with schizophrenia. Neurosci Lett. 2006; 392: 68-71.

49. Doehring A, Hentig NV, Graff J, Salamat S, Schmidt M, Geisslinger $\mathrm{G}$, et al. Genetic variants altering dopamine D2 receptor expression or function modulate the risk of opiate addiction and the dosage requirements of methadone substitution. Pharmacogenet Genomics. 2009; 19: 407-414.

50. Iida $\mathrm{K}$, Akashi $\mathrm{H}$. A test of translational selection at 'silent' sites in the human genome: base composition comparisons in alternatively spliced genes. Gene. 2000; 261: 93-105.

51. Duan J, Wainwright MS, Comeron JM, Saitou N, Sanders AR, Gelernter J, et al. Synonymous mutations in the human dopamine receptor D2 (DRD2) affect mRNA stability and synthesis of the receptor. Hum Mol Genet. 2003; 12: 205-216. 